\title{
Gut Bifidobacteria Populations in Human Health and Aging
}

\author{
Silvia Arboleya ${ }^{1,2}$, Claire Watkins ${ }^{1,2,3}$, Catherine Stanton ${ }^{1,2}$ and R. Paul Ross ${ }^{1,2,4 *}$ \\ ${ }^{1}$ APC Microbiome Institute, University College Cork, Cork, Ireland, ${ }^{2}$ Teagasc Food Research Centre, Moorepark, Fermoy, \\ Cork, Ireland, ${ }^{3}$ School of Microbiology, University College Cork, Cork, Ireland, ${ }^{4}$ School of Science, Engineering and Food \\ Science, University College Cork, Cork, Ireland
}

OPEN ACCESS

Edited by: Marco Ventura, University of Parma, Italy

Reviewed by:

Sinead Christine Leahy, AgResearch, New Zealand

Simone Guglielmetti,

University of Milan, Italy Silvia Turroni,

University of Bologna, Italy

*Correspondence: R. Paul Ross p.ross@ucc.ie

Specialty section: This article was submitted to

Microbial Symbioses,

a section of the journal

Frontiers in Microbiology

Received: 30 May 2016

Accepted: 20 July 2016

Published: 19 August 2016

Citation:

Arboleya S, Watkins C, Stanton C and Ross RP (2016) Gut Bifidobacteria Populations in Human Health and Aging.

Front. Microbiol. 7:1204. doi: 10.3389/fmicb.2016.01204
The intestinal microbiota has increasingly been shown to have a vital role in various aspects of human health. Indeed, several studies have linked alterations in the gut microbiota with the development of different diseases. Among the vast gut bacterial community, Bifidobacterium is a genus which dominates the intestine of healthy breast-fed infants whereas in adulthood the levels are lower but relatively stable. The presence of different species of bifidobacteria changes with age, from childhood to old age. Bifidobacterium longum, B. breve, and B. bifidum are generally dominant in infants, whereas B. catenulatum, B. adolescentis and, as well as B. longum are more prevalent in adults. Increasingly, evidence is accumulating which shows beneficial effects of supplementation with bifidobacteria for the improvement of human health conditions ranging from protection against infection to different extra- and intra-intestinal positive effects. Moreover, bifidobacteria have been associated with the production of a number of potentially health promoting metabolites including short chain fatty acids, conjugated linoleic acid and bacteriocins. The aim of this mini-review is to describe the bifidobacteria compositional changes associated with different stages in life, highlighting their beneficial role, as well as their presence or absence in many disease states.

Keywords: bifidobacteria, intestinal microbiota, health, aging, probiotics

\section{INTRODUCTION}

The study of the intestinal microbiota, linked with its impact on human health, has become a transforming topic in microbiology research. From the pioneering studies using culture-dependent techniques to the current omics' approach, composition and functionality of the intestinal microbiota has been assessed in a wide variety of studies (Lagier et al., 2015). The complex microbiota and the relationships it plays in the prevention and alleviation of diseases have been a major focus of many works (Turnbaugh et al., 2009; Qin et al., 2010; Karlsson et al., 2013). Members of the genus Bifidobacterium have been identified as almost ubiquitous inhabitants of the human host (Biavatti and Mattarelli, 2006), performing an important role in the gut from birth. Due to the traditional interest in bifidobacteria as probiotics this genus has been studied in depth, and changes in the species composition, diversity or relative abundance have been investigated at different stages of life and in several diseases. The aim of this mini-review is to describe the bifidobacteria compositional changes associated with different stages in life, highlighting their beneficial role, as well as the possible role of their presence in the protection against many disease states. 


\section{INTESTINAL MICROBIOTA}

The intestinal microbiota plays an important role in human health and has long been associated with such functions as metabolic, protective, and trophic (Guarner and Malagelada, 2003) and more recently functions related to the gut-brain axis or liver-gut axis (Clarke et al., 2014). The current exponential increase in sequencing and the explosion of other "omics" approaches has allowed us to gain a deep knowledge of intestinal microbiota.

The establishment of the intestinal microbiota was initially considered to occur at birth; however, the presence of microorganisms in placenta or amniotic fluid (Collado et al., 2016) suggests a primary fetal colonization. Moreover, the process is determined by different factors which undoubtedly have an effect on microbiota homeostasis (Penders et al., 2006; Faa et al., 2013). Actinobacteria, followed by Proteobacteria and Firmicutes are the main phyla in early childhood, characterized by low diversity and complexity (Koenig et al., 2011; Turroni et al., 2012). The main changes in gut microbiota composition take place in the first stages of life, getting to a relative stability at 1-2 years old (Voreades et al., 2014). The adult-like structure of the gut microbiota is thought to occur after the 3rd year of life (Koenig et al., 2011; Yatsunenko et al., 2012), and reaches a total number of $10^{14}$ microorganisms, comprising of bacteria, eukarya, viruses and archaeal members (Mihajlovski et al., 2010; HMP, 2012). At phylum level, the gut microbiota is made up of $80-90 \%$ Firmicutes and Bacteroidetes. At species and strain taxonomic level, the diversity is very high in adult life, and is characterized by high interindividual variability (HMP, 2012). However, the functionality and metabolism of the gut microbiota is highly conserved (Qin et al., 2010). Aging was defined by Imahori (1992) as "the regression of physiological function accompanied by advancement of age." It is a natural process which entails changes in the gastrointestinal tract (GIT), immunosenescence and, in some cases, malnutrition (Woodmansey, 2007; Biagi et al., 2012). In addition, alterations in lifestyle, diet and medication have an unavoidable effect on the elderly microbiota composition and function (Biagi et al., 2012; Claesson et al., 2012). Microbial diversity is reduced in old age; however, Bacteroidetes and Firmicutes still constitute the dominant phyla, with increases in the relative abundance of some other Phyla - most notably Proteobacteria (Biagi et al., 2012; Odamaki et al., 2016).

\section{BIFIDOBACTERIA AND THEIR RELEVANCE: FROM THE INFANT-TYPE TO THE AGED-TYPE MICROBIOTA}

Bifidobacteria are normal inhabitants of the GIT belonging to the Actinobacteria phylum. After the depletion of oxygen by facultative anaerobes, bifidobacterial populations are the most abundant genus present in the healthy infant gut (Favier et al., 2002). During adulthood the levels decrease considerably but remain relatively stable; decreasing again in old age (Odamaki et al., 2016; Figure 1). Certain strains of Bifidobacterium are widely used as probiotics - the safety of which is supported by the long historical consumption in fermented milks and the growing knowledge about their physiology and genomes (Arboleya et al., 2016; O'Callaghan and van Sinderen, 2016). The genus Bifidobacterium has been shown to play an important role in the barrier effect, the stimulation of immune system, being associated with a range of beneficial health effects (Picard et al., 2005).

\section{Early Stages of Life}

The initial colonization by bifidobacteria is dependent on a number of extrinsic factors. In terms of vertical transfer, many studies have linked the transmission of bifidobacteria from the mother's vaginal tract, GIT, breast milk, placenta and amniotic fluid to the infant (Makino et al., 2013; Collado et al., 2016). Birth mode, in particular, has a significant impact on this initial colonization, with an increased abundance of bifidobacteria found in infants born vaginally, versus those born by cesarean section (Dominguez-Bello et al., 2010).

Gestational age has been described in terms of its impact on the infant gut, whereby pre-term infants have been characterized in many studies by a dominance of Proteobacteria, with increases in members of Clostridium and Staphylococcus, and much lower levels of Actinobacteria. In contrast, the full-term infant gut has been correlated with much higher levels of Bifidobacterium and Bacteroides, which tend to be dominant in the early weeks of life (Arboleya et al., 2012; Barrett et al., 2013; Arboleya et al., 2015).

Numerous studies investigating the effects of breast feeding versus formula feeding have identified specific bifidobacterial species that correlate with the feeding regime (Roger et al., 2010). Using both culture-dependent and molecular methods, studies have found that Bifidobacterium breve, B. bifidum, B. longum ssp. longum, and B. longum spp. infantis are present in both breast- and formula-fed infants (Mevissen-Verhage et al., 1987; Klaassens et al., 2009). However, B. longum ssp. infantis is more commonly associated with breast fed infants, whereas $B$. longum ssp. longum has been found more commonly amongst bottle-fed infants (Guaraldi and Salvatori, 2012). B. adolescentis, which is commonly found in adults, was found to be present only in formula-fed babies (Klaassens et al., 2009). Numerous studies have focused on the bifidogenic effect that human breast milk has on the infant gut microbiota (Musilova et al., 2014). Specific glycans found within breast milk are known to be utilized by bifidobacteria; however, it has been shown that breast milk provided by mothers with an inactive allele of the Fucosyltransferase 2 gene (FUT2), an enzyme involved in the transfer of fucose to glycans, delays the establishment of bifidobacteria in the infant (Lewis et al., 2015). Similarly, bifidobacteria provide an important role in the breakdown of human milk oligosaccharides (HMOs; Garrido et al., 2013), creating a clear evolutionary link between the mother, infant and the microbial species present. Indeed, B. longum ssp. infantis has specifically been studied for its ability to digest different HMO structures (Sela et al., 2008). This species is also associated with anti-inflammatory properties, and the ability to decrease intestinal permeability (Underwood et al., 2015). The growth of infant-derived Bifidobacterium, B. longum ssp. infantis, and B. bifidum, in the presence of HMOs has also been shown 


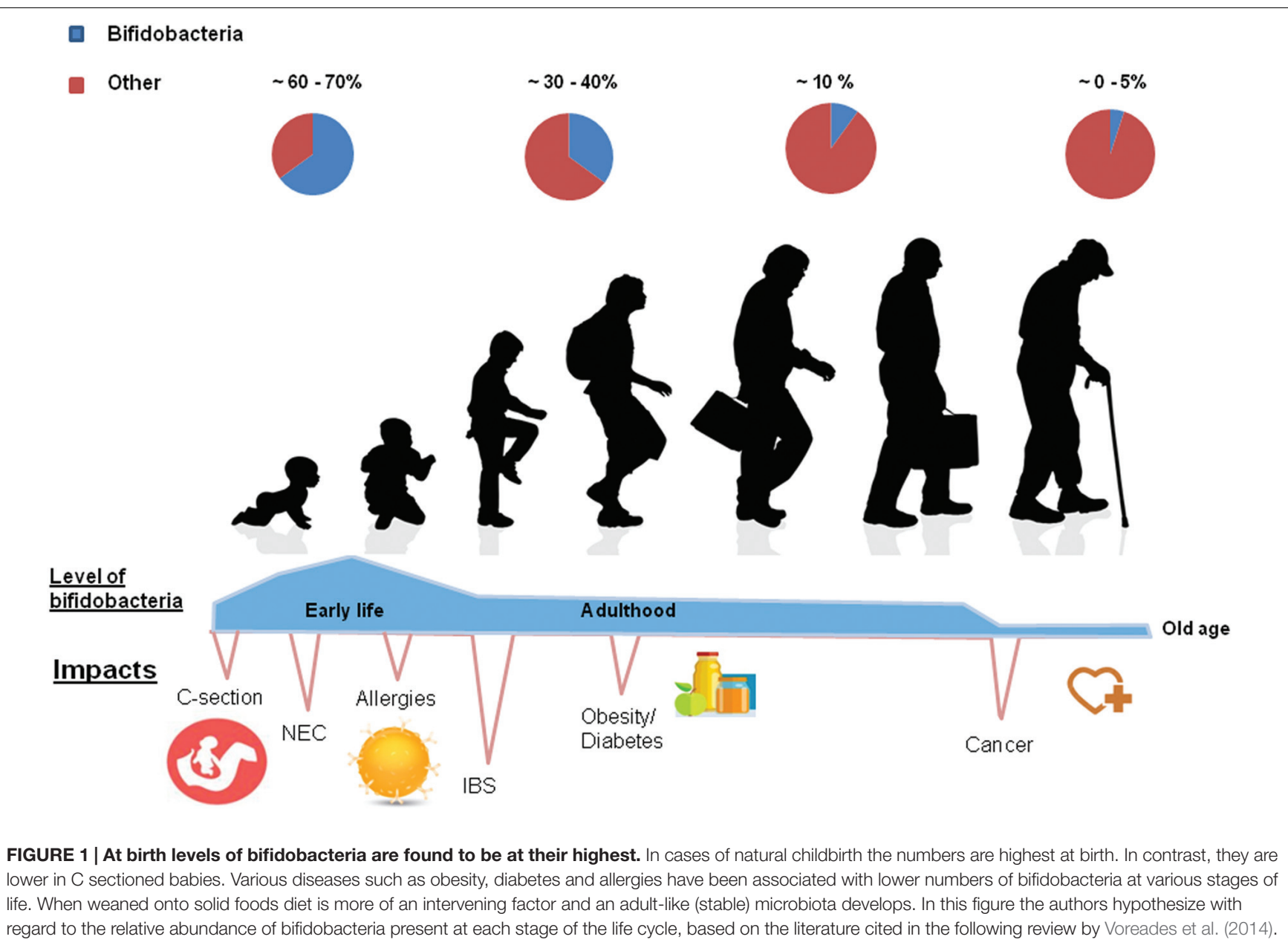

to promote the adhesive properties of these strains, as well as the expression of anti-inflammatory cytokines and tight junction proteins in eukaryotic cells (Chichlowski et al., 2012). Interestingly, a study published by Del Chierico et al. (2015) focused on the co-correlation between the metabolome and the OTUs occurrence in infant stool samples. Results found that Bifidobacterium OTUs were positively correlated with the presence of lactate and alanine during this 1st month of life. Another recent work, negatively correlated the lactase gene with Bifidobacterium levels in the gut microbiota of twins, speculating that lactase-persisters babies harbor lower levels of bifidobacteria because of low lactose availability (Goodrich et al., 2016).

In terms of species, B. longum, B. breve, and B. bifidum are most abundant (Table 1) in infants (Favier et al., 2002; Gueimonde et al., 2007; Turroni et al., 2012). A recent study described the different Bifidobacterium species profile between monozygotic twins (entirely dominated by B. breve) and their fraternal sibling (exhibiting higher species diversity) at 1 month of life (Murphy et al., 2015; Table 1).

\section{Adulthood and Old Age}

In adulthood, the levels of bifidobacteria are lower (2-14\% relative abundance) but remain stable (Odamaki et al., 2016).
Gueimonde et al. (2007) identified significantly higher levels of Bifidobacterium in infants than in adults by q-PCR technique. They postulated that $B$. longum is the most widely abundant species, which is in agreement with other studies (Gavini et al., 2001; Matsuki et al., 2004). However, Matsuki et al. (2004) observed higher levels of $B$. adolescentis and B. catenulatum in their adult population. Chaplin et al. (2015) reported a decreased frequency of isolation of $B$. bifidum and $B$. breve with age and an increased trend in $B$. adolescentis.

Currently, there is no agreed definition of old-age-specific gut microbiota profile due to the high inter-individual variability, differences in diet and lifestyle, and the unclear definition of the term "elderly." However, some trends are repetitively observed such as the decrease of bifidobacteria in the elderly population, confirmed by several studies using different technologies (Mitsuoka et al., 1974; Mitsuoka, 1992; Gavini et al., 2001; Hopkins et al., 2001; Gueimonde et al., 2010; Biagi et al., 2012; Salazar et al., 2013). Woodmansey et al. (2004) reported that the decline in bifidobacteria population with aging was accompanied by a decrease in species diversity. This decline was associated with the reduction in adhesion to the intestinal mucosa, but it is not clear if it is due to the changes in the microbiota or in the structure of mucus (He et al., 2001). 
TABLE 1 | (A) Distribution of the most abundant Bifidobacterium species in the intestinal microbiota at different stages of life analyzed using different techniques.

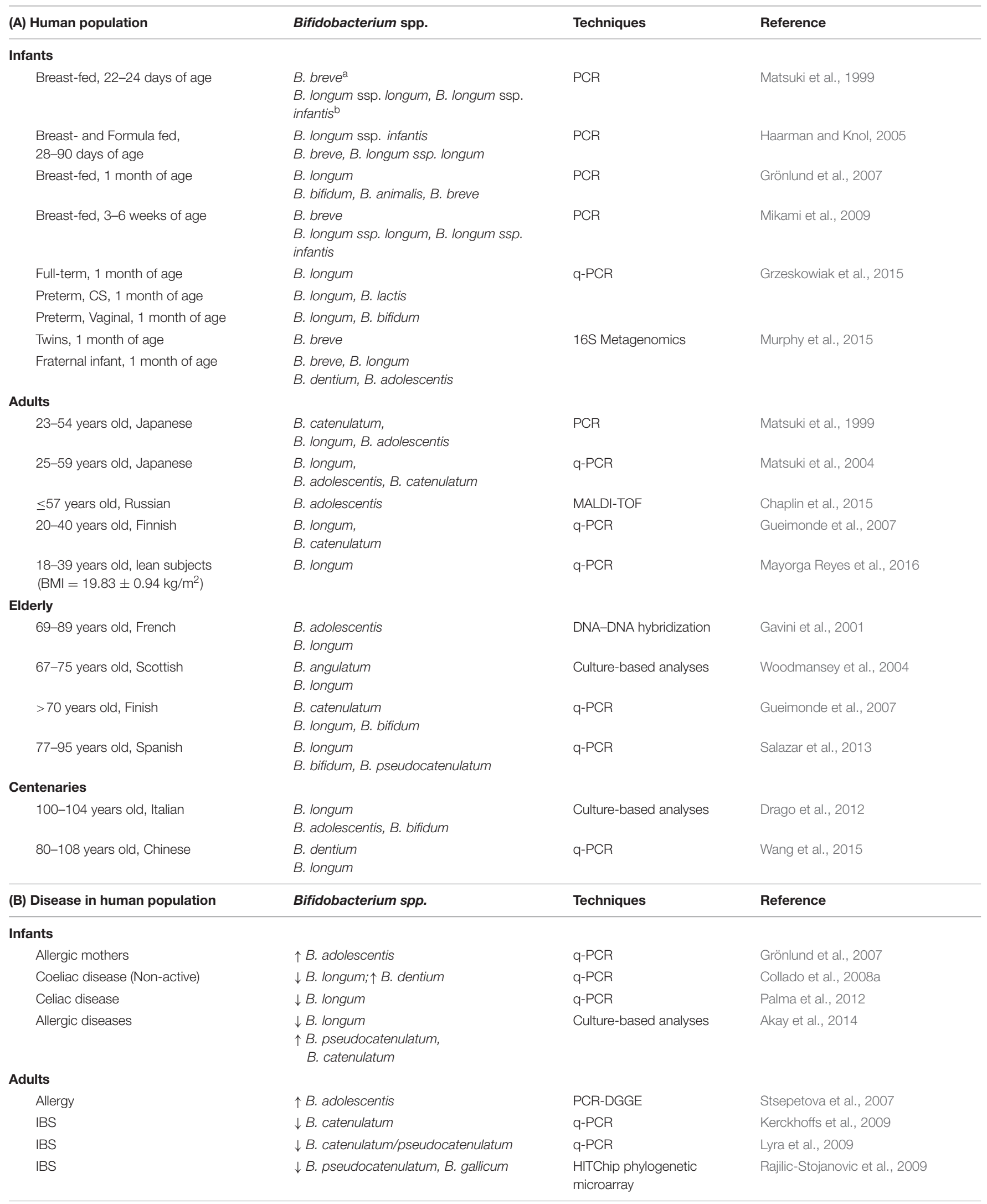


TABLE 1 | Continued

\begin{tabular}{|c|c|c|c|}
\hline (B) Disease in human population & Bifidobacterium spp. & Techniques & Reference \\
\hline IBS & $\uparrow$ B. adolescentis & 16S Metagenomics & Jeffery et al., 2012 \\
\hline Hepatitis B virus-related cirrhosis & $\begin{array}{l}\uparrow \text { B. dentium } \\
\downarrow \text { B. catenulatum, B. longum }\end{array}$ & PCR-DGGE and q-PCR & Xu et al., 2012 \\
\hline Obesity & $\downarrow B$. animalis & $\mathrm{q}-\mathrm{PCR}$ & Million et al., 2013 \\
\hline Cystic fibrosis & $\begin{array}{l}\downarrow \text { B. catenulatum/pseudocatenulatum, } \\
\text { B. longum, B. adolescentis }\end{array}$ & PCR-DGGE & Duytschaever et al., 2013 \\
\hline Long-term asthma & $\uparrow B$. adolescentis & 16S Metagenomics & Hevia et al., 2016 \\
\hline
\end{tabular}

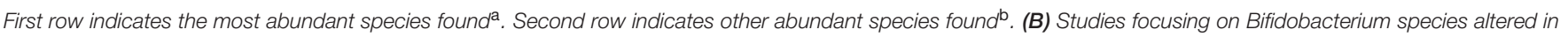
certain diseases.

$\uparrow$ Increased levels; $\downarrow$ Decreased levels.

The bifidobacteria composition in centenary populations was also reported in some studies; however, the results remain somewhat controversial. In a European population, the microbiota composition of centenarians was still similar to that of adults (Biagi et al., 2010), however, higher proportions of bifidobacteria were found in centenarians than in younger elderlies from a region of China (Zhao et al., 2011). Regarding species (Table 1), B. longum was the most abundant in Italian centenarians followed by B. adolescentis and B. bifidum (Drago et al., 2012), but $B$. dentium was dominant in Chinese centenaries (Wang et al., 2015).

Other extrinsic factors indirectly related to the aging process also affect the bifidobacteria composition. The extended use of antibiotics in the older population undoubtedly has a huge impact on the intestinal microbiota composition, decreasing the bifidobacteria population (Woodmansey et al., 2004; O'Sullivan et al., 2013). While antibiotics remain an essential medical tool, therapies targeted toward the reestablishment of microbiota have been explored, in particular the use of probiotics to correct the imbalance in the bifidobacteria population and the alteration in the intestinal microbiota after antibiotic therapy (Rondanelli et al., 2015). In terms of frailty, van Tongeren et al. (2005) did not find differences in bifidobacteria between elderly people divided into a low and high frailty category. The same trend was observed by Bartosch et al. (2004) between elderly living in the local community and elderly in a hospitalized environment.

\section{BIFIDOBACTERIA AND DISEASES}

Several diseases, both intra- and extra-intestinal, have been associated with alterations in the gut microbiota composition and function (Wu and Lewis, 2013). Although, there is still not a detailed description of "potential alterated-microbiota types," some authors postulate that intestinal microbial alterations could be the prelude to a wide range of disease (Putignani et al., 2014).

\section{Bifidobacterial Composition in Diseases}

Given the widespread use of bifidobacteria as probiotics, they have been studied extensively and as such the aberrancies in bifidobacteria species composition, diversity or changes in their relative abundance have been reported in several diseases.

Obesity is a worldwide disease affecting children and adults, which is commonly associated with alterations in the microbiota. Some studies have shown lower levels of bifidobacteria, linked to higher prevalence of enterobacteria or Staphylococcus in obese children (Kalliomäki et al., 2008; Gao et al., 2015). Interestingly, women who gain weight during pregnancy have displayed lower levels of Bifidobacterium in contrast to healthy weight pregnant women (8.36 vs. $9.10 \mathrm{log}$ genome equivalents/g feces; Santacruz et al., 2010). These results are correlated with the decreased levels of bifidobacteria in babies whose mother gained significant weight during pregnancy (Collado et al., 2008b), that is over and above the pregnancy itself. In terms of allergic disease, Hevia et al. (2016) observed lower levels of Bifidobacterium in patients with long-term asthma. The same study showed a dominance of $B$. adolescentis in both short- and long-term asthmatic individuals, in concordance with other previous studies (Stsepetova et al., 2007). This species was only found in infants of allergic mothers, who displayed lower levels of bifidobacteria in their breast milk (Grönlund et al., 2007). One particular Turkish study described a statistical difference between the increased levels of $B$. longum in healthy children (30.3\%) when compared to children with allergic disease (11.1\%), suggesting that B. longum may play a beneficial role in the disease and thus may be useful as a probiotic for the prevention of allergic pathologies (Akay et al., 2014). Different studies have focused on the relationship between the intestinal microbiota and the pathogenesis of irritable bowel syndrome (IBS), showing an altered microbiota related to IBS patients and lower levels in the Bifidobacterium genus (Taverniti and Guglielmetti, 2014).

In the elderly gut microbiota, Hopkins and Macfarlane (2002) focused on the impact of Clostridium difficile-associated diarrhea, describing a reduction in numbers of bifidobacteria in elderly people suffering the infection compared to a healthy control group. Decreased numbers of bifidobacteria have also been observed in other illnesses such as cystic fibrosis, hepatitis $\mathrm{B}$ and both diabetes Types I and II (Wu et al., 2010; $\mathrm{Xu}$ et al., 2012; Duytschaever et al., 2013; Murri et al., 2013).

Overall, there is a repetitive trend between lower bifidobacteria and a variety of common disease states, suggesting a role 
of bifidobacteria in health. However, whether bifidobacteria numbers have any causal relationship to any of these conditions remains unknown.

\section{Bifidobacteria as Probiotics in Diseases}

Numerous health-promoting effects have been ascribed to strains of the Bifidobacterium genus based on their use as probiotics in intervention strategies to address many ill health conditions.

In that regard, the capability of bifidobacteria to stimulate the immune system seems to be species specific as shown in a particular study where the effect of infant derived bifidobacteria on the T-helper $1\left(\mathrm{~T}_{\mathrm{H}} 1\right) / \mathrm{T}_{\mathrm{H}} 2$ balance was examined. Results published by Ménard et al. (2008) demonstrated that B. bifidum, $B$. dentium, and B. longum were capable of stimulating systemic and intestinal immunity. It is not surprising that bifidobacteria are so widely used as probiotics in the treatment and prevention of infant disease given their dominance in the infant gut. Their application in pathologies such as allergies, celiac disease, obesity, diarrheas, colic, infections or necrotizing enterocolitis has returned very good results (Di Gioia et al., 2014). They have also been extensively used in adults and elderly, in the treatment of gastrointestinal and respiratory diseases (Biagi et al., 2012; Malaguarnera et al., 2012; Tojo et al., 2014). In an attempt to restore the lipoprotein imbalance found in the blood of children with dyslipidemia, Guardamagna et al. (2014) examined the effects of a probiotic which contained three Bifidobacterium strains, selected due to their bile salt hydrolase activity. Their results found a decrease in total cholesterol and low-density lipoprotein cholesterol.

In terms of brain gut disorders, several studies have examined the use of bifidobacteria for their psychobiotic effects in reducing stress, anxiety and depressive like behavior in BALB/c mice. It was concluded that the behavioral effects observed may be partially explained by the differential effects on the immune system, although mechanisms underlying the effects are unknown (Savignac et al., 2014). Furthermore, a particular strain of B. longum was shown to have anxiolytic effects in a model of non-infectious colitis through vagal pathways whereby the fermentation products of this species were capable of modifying the excitation of enteric neurons in the gut (Bercik et al., 2011).

Bifidobacteria have also been studied for their ability to specifically localize at tumor sites (Nakamura et al., 2002). Cronin et al. (2010) showed in that B. breve UCC 2003 was able to target tumors in athymic MF1 nu/nu mice bearing s.c. B16-F10 murine melanoma tumors, as well as C57 mice bearing s.c. Lewis lung carcinoma tumors. Interestingly, an increasing bacterial load of $B$. breve UCC 2003 was found in the metastatic nodules in the lungs of the B-16 mouse model where oxygen is transferred.

\section{REFERENCES}

Akay, H. K., Bahar Tokman, H., Hatipoglu, N., Hatipoglu, H., Siraneci, R., Demirci, M., et al. (2014). The relationship between bifidobacteria and allergic asthma and/or allergic dermatitis: a prospective study of $0-3$ years-old children in Turkey. Anaerobe 28, 98-103. doi: 10.1016/j.anaerobe.2014.05.006

Arboleya, S., Binetti, A., Salazar, N., Fernandez, N., Solis, G., HernandezBarranco, A., et al. (2012). Establishment and development of intestinal
Bifidobacteria have also been shown to have an effect on tumor specific T-cell responses in C57BL/6 mice bearing s.c. B16.SIY melanoma growth (Sivan et al., 2015). In this study bifidobacteria were found to have an effect on dendritic cell function and CD8+ $\mathrm{T}$ cell responses, reducing tumor cell growth.

Bifidobacterium species may have positive effects on human health, while it should be stressed that the increase only in fecal bifidobacteria level cannot in itself a health benefit. However, given the strong association of bifidobacteria to health it may provide a contributory biomarker to disease status lined to some illnesses in the future. Moreover the use of bifidobacteria as delivery vehicles for the administration of therapeutic agents to target tumors due to their anaerobic nature, is a very promising and safe form of therapy for this disease state.

\section{CONCLUSION}

Bifidobacteria are one of the most abundant genera present in the healthy infant gut and represent a significant portion of the microbiota throughout a healthy adult life, playing an important role in gut homeostasis and health. During late adulthood and within several diseases, the levels of Bifidobacterium and its species diversity decrease. Nowadays, their association with health and aging is undeniable, however, the jury is still out on whether it is a "cause" or "effect" type relationship. Given the prevalence of bifidobacteria at various stages of a healthy life and the many health promoting attributes associated with their use, it is undoubted that these bacteria play an important role in human health maintenance and protection and also may in the future provide a very important biomarker for certain diseases.

\section{AUTHOR CONTRIBUTIONS}

RR, CS, and SA conceived the manuscript. SA and CW drafted the manuscript. CS and RR reviewed the final version of the manuscript. All the authors approved it for publication.

\section{ACKNOWLEDGMENTS}

This research was supported by the Science Foundation Ireland (SFI)-funded APC Microbiome Institute; by Department of Agriculture Food and Marine (DAFM)-funded INFANTMET (Ref. No. 10FDairy) and ToddlerFood (Ref. No. 14F821) projects; and by European Union's Seventh Framework Program (EUFP7)-funded MyNewGut project (Ref. No. 613979). microbiota in preterm neonates. FEMS Microbiol. Ecol. 79, 763-772. doi: 10.1111/j.1574-6941.2011.01261.x

Arboleya, S., Sánchez, B., Milani, C., Duranti, S., Solís, G., Fernández, N., et al. (2015). Intestinal microbiota development in preterm neonates and effect of perinatal antibiotics. J. Pediatr. 166, 538-544. doi: 10.1016/j.jpeds.2014.09.041

Arboleya, S., Stanton, C., Ryan, C. A., Dempsey, E., and Ross, P. R. (2016). Bosom Buddies: the symbiotic relationship between infants and Bifidobacterium longum ssp. longum and ssp. infantis. Genetic and probiotic features. 
Annu. Rev. Food Sci. Technol. 7, 1-21. doi: 10.1146/annurev-food-041715033151

Barrett, E., Kerr, C., Murphy, K., O’Sullivan, O., Ryan, C. A., Dempsey, E. M., et al. (2013). The individual-specific and diverse nature of the preterm infant microbiota. Arch. Dis. Child. Fetal Neonatal Ed. 98, F334-F340. doi: 10.1136/archdischild-2012-303035

Bartosch, S., Fite, A., Macfarlane, G. T., and McMurdo, M. E. T. (2004). Characterization of bacterial communities in feces from healthy elderly volunteers and hospitalized elderly patients by using real-time PCR and effects of antibiotic treatment on the fecal microbiota. Appl. Environ. Microbiol. 70, 3575-3581. doi: 10.1128/AEM.70.6.3575-3581.2004

Bercik, P., Park, A. J., Sinclair, D., Khoshdel, A., Lu, J., Huang, X., et al. (2011). The anxiolytic effect of Bifidobacterium longum NCC3001 involves vagal pathways for gut-brain communication. Neurogastroenterol. Motil. 23, 1132-1139. doi: 10.1111/j.1365-2982.2011.01796.x

Biagi, E., Candela, M., Fairweather-Tait, S., Franceschi, C., and Brigidi, P. (2012). Ageing of the human metaorganism: the microbial counterpart. Age 34, 247267. doi: 10.1007/s11357-011-9217-5

Biagi, E., Nylund, L., Candela, M., Ostan, R., Bucci, L., Pini, E., et al. (2010). Through ageing and beyond: gut microbiota and inflammatory status in seniors and centenarians. PLoS ONE 5:e10667. doi: 10.1371/journal.pone.0010667

Biavatti, B., and Mattarelli, P. (2006). "The family Bifidobacteriaceae," in The Prokaryotes, 3rd Edn, Vol. 3, eds S. Falkow, E. Rosenberg, K. H. Schleifir, E. Stackebrandt, and M. Dworkin (New York, NY: Springer - Verlag GmbH), 322-382. doi: 10.1007/0-387-30743-5_17

Chaplin, A. V., Brzhozovskii, A. G., Parfenova, T. V., Kafarskaia, L. I., Volodin, N. N., Shkoporov, A. N., et al. (2015). Species diversity of bifidobacteria in the intestinal microbiota studied using MALDI-TOF mass-spectrometry. Vestn. Ross. Akad. Med. Nauk 4, 435-440.

Chichlowski, M., De Lartigue, G., German, J. B., Raybould, H. E., and Mills, D. A. (2012). Bifidobacteria isolated from infants and cultured on human milk oligosaccharides affect intestinal epithelial function. J. Pediatr. Gastroenterol. Nutr. 55, 321-327. doi: 10.1097/MPG.0b013e31824fb899

Claesson, M. J., Jeffery, I. B., Conde, S., Power, S. E., O’Connor, E. M., Cusack, S., et al. (2012). Gut microbiota composition correlates with diet and health in the elderly. Nature 488, 178-184. doi: 10.1038/nature11319

Clarke, G., Stilling, R. M., Kennedy, P. J., Stanton, C., Cryan, J. F., and Dinan, T. G. (2014). Minireview: gut microbiota: the neglected endocrine organ. Mol. Endocrinol. 28, 1221-1238. doi: 10.1210/me.2014-1108

Collado, M. C., Donat, E., Ribes-Koninckx, C., Calabuig, M., and Sanz, Y. (2008a). Imbalances in faecal and duodenal Bifidobacterium species composition in active and non-active coeliac disease. BMC Microbiol. 8:232. doi: 10.1186/14712180-8-232

Collado, M. C., Isolauri, E., Laitinen, K., and Salminen, S. (2008b). Distinct composition of gut microbiota during pregnancy in overweight and normalweight women. Am. J. Clin. Nutr. 88, 894-899.

Collado, M. C., Rautava, S., Aakko, J., Isolauri, E., and Salminen, S. (2016). Human gut colonisation may be initiated in utero by distinct microbial communities in the placenta and amniotic fluid. Sci. Rep. 6, 23129. doi: 10.1038/srep23129

Cronin, M., Morrissey, D., Rajendran, S., El Mashad, S. M., van Sinderen, D., O'Sullivan, G. C., et al. (2010). Orally administered bifidobacteria as vehicles for delivery of agents to systemic tumors. Mol. Ther. 18, 1397-1407. doi: $10.1038 / \mathrm{mt} .2010 .59$

Del Chierico, F., Vernocchi, P., Petrucca, A., Paci, P., Fuentes, S., Pratico, G., et al. (2015). Phylogenetic and metabolic tracking of gut microbiota during perinatal development. PLoS ONE 10:e0137347. doi: 10.1371/journal.pone.0137347

Di Gioia, D., Aloisio, I., Mazzola, G., and Biavati, B. (2014). Bifidobacteria: their impact on gut microbiota composition and their applications as probiotics in infants. Appl. Microbiol. Biotechnol. 98, 563-577. doi: 10.1007/s00253-0135405-9

Dominguez-Bello, M. G., Costello, E. K., Contreras, M., Magris, M., Hidalgo, G., Fierer, N., et al. (2010). Delivery mode shapes the acquisition and structure of the initial microbiota across multiple body habitats in newborns. Proc. Natl. Acad. Sci. U.S.A. 107, 11971-11975. doi: 10.1073/pnas.1002601107

Drago, L., Toscano, M., Rodighiero, V., De Vecchi, E., and Mogna, G. (2012). Cultivable and pyrosequenced fecal microflora in centenarians and young subjects. J. Clin. Gastroenterol. 46(Suppl.), S81-S84. doi: 10.1097/MCG.0b013e3182693982
Duytschaever, G., Huys, G., Bekaert, M., Boulanger, L., De Boeck, K., and Vandamme, P. (2013). Dysbiosis of bifidobacteria and Clostridium cluster XIVa in the cystic fibrosis fecal microbiota. J. Cyst. Fibros. 12, 206-215. doi: 10.1016/j.jcf.2012.10.003

Faa, G., Gerosa, C., Fanni, D., Nemolato, S., van Eyken, P., and Fanos, V. (2013). Factors influencing the development of a personal tailored microbiota in the neonate, with particular emphasis on antibiotic therapy. J. Matern. Fetal Neonatal Med. 26(Suppl. 2), 35-43. doi: 10.3109/14767058.2013. 829700

Favier, C. F., Vaughan, E. E., De Vos, W. M., and Akkermans, A. D. (2002). Molecular monitoring of succession of bacterial communities in human neonates. Appl. Environ. Microbiol. 68, 219-226. doi: 10.1128/AEM.68.1.219226.2002

Gao, X., Jia, R., Xie, L., Kuang, L., Feng, L., and Wan, C. (2015). Obesity in school-aged children and its correlation with gut E. coli and Bifidobacteria: a case-control study. BMC Pediatr. 15:64. doi: 10.1186/s12887-015-0384-x

Garrido, D., Dallas, D. C., and Mills, D. A. (2013). Consumption of human milk glycoconjugates by infant-associated bifidobacteria: mechanisms and implications. Microbiology 159(Pt 4), 649-664. doi: 10.1099/mic.0.064113-0

Gavini, F., Cayuela, C., Antoine, J.-M., Lecoq, C., Lefebvre, B., Membré, J.M., et al. (2001). Differences in the distribution of bifidobacterial and enterobacterial species in human faecal microflora of three different (children, adults, elderly) age groups. Microb. Ecol. Health Dis. 13, 40-45. doi: $10.1080 / 089106001750071690$

Goodrich, J. K., Davenport, E. R., Beaumont, M., Jackson, M. A., Knight, R., Ober, C., et al. (2016). Genetic determinants of the gut microbiome in UK twins. Cell Host Microbe 19, 731-743. doi: 10.1016/j.chom.2016.04.017

Grönlund, M. M., Gueimonde, M., Laitinen, K., Kociubinski, G., Gronroos, T., Salminen, S., et al. (2007). Maternal breast-milk and intestinal bifidobacteria guide the compositional development of the Bifidobacterium microbiota in infants at risk of allergic disease. Clin. Exp. Allergy 37, 1764-1772. doi: 10.1111/j.1365-2222.2007.02849.x

Grzeskowiak, L., Sales Teixeira, T. F., Bigonha, S. M., Lobo, G., Salminen, S., and Ferreira, C. L. (2015). Gut Bifidobacterium microbiota in onemonth-old Brazilian newborns. Anaerobe 35( $\mathrm{Pt} \quad \mathrm{B}), \quad 54-58$. doi: 10.1016/j.anaerobe.2015.07.004

Guaraldi, F., and Salvatori, G. (2012). Effect of breast and formula feeding on gut microbiota shaping in newborns. Front. Cell. Infect. Microbiol. 2:94. doi: 10.3389/fcimb.2012.00094

Guardamagna, O., Amaretti, A., Puddu, P. E., Raimondi, S., Abello, F., Cagliero, P., et al. (2014). Bifidobacteria supplementation: effects on plasma lipid profiles in dyslipidemic children. Nutrition 30, 831-836. doi: 10.1016/j.nut.2014.01.014

Guarner, F., and Malagelada, J. R. (2003). Gut flora in health and disease. Lancet 361, 512-519. doi: 10.1016/S0140-6736(03)12489-0

Gueimonde, M., Debor, L., Tölkkö, S., Jokisalo, E., and Salminen, S. (2007). Quantitative assessment of faecal bifidobacterial populations by real-time PCR using lanthanide probes. J. Appl. Microbiol. 102, 1116-1122. doi: 10.1111/j.1365-2672.2006.03145.x

Gueimonde, M., Ouwehand, A., Pitkälä, K., Strandberg, T., Finne-Soveri, H., and Salminen, S. (2010). Fecal Bifidobacterium levels in elderly nursing home patients - Are levels as expected? Biosci. Microflora 29, 111-113. doi: 10.12938/bifidus.29.111

Haarman, M., and Knol, J. (2005). Quantitative real-time PCR assays to identify and quantify fecal Bifidobacterium species in infants receiving a prebiotic infant formula. Appl. Environ. Microbiol. 71, 2318-2324. doi: 10.1128/aem.71.5.23182324.2005

He, F., Ouwehand, A. C., Isolauri, E., Hosoda, M., Benno, Y., and Salminen, S. (2001). Differences in composition and mucosal adhesion of bifidobacteria isolated from healthy adults and healthy seniors. Curr. Microbiol. 43, 351-354. doi: $10.1007 / \mathrm{s} 002840010315$

Hevia, A., Milani, C., Lopez, P., Donado, C. D., Cuervo, A., Gonzalez, S., et al. (2016). Allergic patients with long-term asthma display low levels of Bifidobacterium adolescentis. PLOS ONE 11:e0147809. doi: 10.1371/journal.pone.0147809

HMP (2012). Structure, function and diversity of the healthy human microbiome. Nature 486, 207-214. doi: 10.1038/nature11234

Hopkins, M., Sharp, R., and Macfarlane, G. (2001). Age and disease related changes in intestinal bacterial populations assessed by cell culture, 16S rRNA 
abundance, and community cellular fatty acid profiles. Gut 48, 198-205. doi: $10.1136 /$ gut.48.2.198

Hopkins, M. J., and Macfarlane, G. T. (2002). Changes in predominant bacterial populations in human faeces with age and with Clostridium difficile infection. J. Med. Microbiol. 51, 448-454. doi: 10.1099/0022-1317-51-5-448

Imahori, K. (1992). How I understand aging. Nutr. Rev. 50, 351-352. doi: 10.1111/j.1753-4887.1992.tb02477.x

Jeffery, I. B., O’Toole, P. W., Ohman, L., Claesson, M. J., Deane, J., Quigley, E. M., et al. (2012). An irritable bowel syndrome subtype defined by species-specific alterations in faecal microbiota. Gut 61, 997-1006. doi: 10.1136/gutjnl-2011301501

Kalliomäki, M., Collado, M. C., Salminen, S., and Isolauri, E. (2008). Early differences in fecal microbiota composition in children may predict overweight. Am. J. Clin. Nutr. 87, 534-538.

Karlsson, F. H., Tremaroli, V., Nookaew, I., Bergstrom, G., Behre, C. J., Fagerberg, B., et al. (2013). Gut metagenome in European women with normal, impaired and diabetic glucose control. Nature 498, 99-103. doi: $10.1038 /$ nature 12198

Kerckhoffs, A. P., Samsom, M., van der Rest, M. E., de Vogel, J., Knol, J., BenAmor, K., et al. (2009). Lower Bifidobacteria counts in both duodenal mucosaassociated and fecal microbiota in irritable bowel syndrome patients. World J. Gastroenterol. 15, 2887-2892. doi: 10.3748/wjg.15.2887

Klaassens, E. S., Boesten, R. J., Haarman, M., Knol, J., Schuren, F. H., Vaughan, E. E., et al. (2009). Mixed-species genomic microarray analysis of fecal samples reveals differential transcriptional responses of bifidobacteria in breast- and formula-fed infants. Appl. Environ. Microbiol. 75, 2668-2676. doi: 10.1128/AEM.02492-08

Koenig, J. E., Spor, A., Scalfone, N., Fricker, A. D., Stombaugh, J., Knight, R., et al. (2011). Succession of microbial consortia in the developing infant gut microbiome. Proc. Natl. Acad. Sci. U.S.A. 108(Suppl. 1), 4578-4585. doi: 10.1073/pnas.1000081107

Lagier, J. C., Hugon, P., Khelaifia, S., Fournier, P. E., La Scola, B., and Raoult, D. (2015). The rebirth of culture in microbiology through the example of culturomics to study human gut microbiota. Clin. Microbiol. Rev. 28, 237-264. doi: $10.1128 / \mathrm{cmr} .00014-14$

Lewis, Z. T., Totten, S. M., Smilowitz, J. T., Popovic, M., Parker, E., Lemay, D. G., et al. (2015). Maternal fucosyltransferase 2 status affects the gut bifidobacterial communities of breastfed infants. Microbiome 3, 13. doi: 10.1186/s40168-0150071-z

Lyra, A., Rinttila, T., Nikkila, J., Krogius-Kurikka, L., Kajander, K., Malinen, E., et al. (2009). Diarrhoea-predominant irritable bowel syndrome distinguishable by $16 \mathrm{~S}$ rRNA gene phylotype quantification. World J. Gastroenterol. 15, 59365945. doi: $10.3748 /$ wjg. 15.5936

Makino, H., Kushiro, A., Ishikawa, E., Kubota, H., Gawad, A., Sakai, T., et al. (2013). Mother-to-infant transmission of intestinal bifidobacterial strains has an impact on the early development of vaginally delivered infant's microbiota. PLOS ONE 8:e78331. doi: 10.1371/journal.pone.0078331

Malaguarnera, G., Leggio, F., Vacante, M., Motta, M., Giordano, M., Bondi, A., et al. (2012). Probiotics in the gastrointestinal diseases of the elderly. J. Nutr. Health Aging 16, 402-410. doi: 10.1007/s12603-011-0357-1

Matsuki, T., Watanabe, K., Fujimoto, J., Kado, Y., Takada, T., Matsumoto, K., et al. (2004). Quantitative PCR with $16 \mathrm{~S}$ rRNA-gene-targeted species-specific primers for analysis of human intestinal bifidobacteria. Appl. Environ. Microbiol. 70, 167-173. doi: 10.1128/AEM.70.1.167-173.2004

Matsuki, T., Watanabe, K., Tanaka, R., Fukuda, M., and Oyaizu, H. (1999). Distribution of bifidobacterial species in human intestinal microflora examined with $16 \mathrm{~S}$ rRNA-gene-targeted species-specific primers. Appl. Environ. Microbiol. 65, 4506-4512.

Mayorga Reyes, L., Gonzalez Vazquez, R., Cruz Arroyo, S. M., Melendez Avalos, A., Reyes Castillo, P. A., Chavaro Perez, D. A., et al. (2016). Correlation between diet and gut bacteria in a population of young adults. Int. J. Food Sci. Nutr. 67, 470-478. doi: 10.3109/09637486.2016.1162770

Ménard, O., Butel, M. J., Gaboriau-Routhiau, V., and Waligora-Dupriet, A. J. (2008). Gnotobiotic mouse immune response induced by Bifidobacterium sp. strains isolated from infants. Appl. Environ. Microbiol. 74, 660-666. doi: 10.1128/aem.01261-07

Mevissen-Verhage, E. A., Marcelis, J. H., de Vos, M. N., Harmsen-van Amerongen, W. C., and Verhoef, J. (1987). Bifidobacterium, Bacteroides, and Clostridium spp. in fecal samples from breast-fed and bottle-fed infants with and without iron supplement. J. Clin. Microbiol. 25, 285-289.

Mihajlovski, A., Doré, J., Levenez, F., Alric, M., and Brugère, J.-F. (2010). Molecular evaluation of the human gut methanogenic archaeal microbiota reveals an ageassociated increase of the diversity. Environ. Microbiol. Rep. 2, 272-280. doi: 10.1111/j.1758-2229.2009.00116.x

Mikami, K., Takahashi, H., Kimura, M., Isozaki, M., Izuchi, K., Shibata, R., et al. (2009). Influence of maternal bifidobacteria on the establishment of bifidobacteria colonizing the gut in infants. Pediatr. Res. 65, 669-674. doi: 10.1203/PDR.0b013e31819ed7a8

Million, M., Angelakis, E., Maraninchi, M., Henry, M., Giorgi, R., Valero, R., et al. (2013). Correlation between body mass index and gut concentrations of Lactobacillus reuteri, Bifidobacterium animalis, Methanobrevibacter smithii and Escherichia coli. Int. J. Obes. (Lond.) 37, 1460-1466. doi: 10.1038/ijo.2013.20

Mitsuoka, T. (1992). Intestinal flora and aging. Nutr. Rev. 50, 438-446. doi: 10.1111/j.1753-4887.1992.tb02499.x

Mitsuoka, T., Hayakawa, K., and Kimura, N. (1974). [The faecal flora of man. II. The composition of Bifidobacterium flora of different age groups (author's transl)]. Zentralbl. Bakteriol. Orig. A 226, 469-478.

Murphy, K., O’ Shea, C. A., Ryan, C. A., Dempsey, E. M., O’ Toole, P. W., Stanton, C., et al. (2015). The gut microbiota composition in dichorionic triplet sets suggests a role for host genetic factors. PLoS ONE 10:e0122561. doi: 10.1371/journal.pone.0122561

Murri, M., Leiva, I., Gomez-Zumaquero, J. M., Tinahones, F. J., Cardona, F., Soriguer, F., et al. (2013). Gut microbiota in children with type 1 diabetes differs from that in healthy children: a case-control study. BMC Med. 11:46. doi: 10.1186/1741-7015-11-46

Musilova, S., Rada, V., Vlkova, E., and Bunesova, V. (2014). Beneficial effects of human milk oligosaccharides on gut microbiota. Benef. Microbes 5, 273-283. doi: $10.3920 / \mathrm{bm} 2013.0080$

Nakamura, T., Sasaki, T., Fujimori, M., Yazawa, K., Kano, Y., Amano, J., et al. (2002). Cloned cytosine deaminase gene expression of Bifidobacterium longum and application to enzyme/pro-drug therapy of hypoxic solid tumors. Biosci. Biotechnol. Biochem. 66, 2362-2366. doi: 10.1271/bbb.66.2362

O'Callaghan, A., and van Sinderen, D. (2016). Bifidobacteria and their role as members of the human gut microbiota. Front. Microbiol. 7:925. doi: $10.3389 /$ fmicb.2016.00925

Odamaki, T., Kato, K., Sugahara, H., Hashikura, N., Takahashi, S., Xiao, J. Z., et al. (2016). Age-related changes in gut microbiota composition from newborn to centenarian: a cross-sectional study. BMC Microbiol. 16:90. doi: 10.1186/s12866-016-0708-5

O'Sullivan, O., Coakley, M., Lakshminarayanan, B., Conde, S., Claesson, M. J., Cusack, S., et al. (2013). Alterations in intestinal microbiota of elderly Irish subjects post-antibiotic therapy. J. Antimicrob. Chemother. 68, 214-221. doi: $10.1093 / \mathrm{jac} / \mathrm{dks} 348$

Palma, G. D., Capilla, A., Nova, E., Castillejo, G., Varea, V., Pozo, T., et al. (2012). Influence of milk-feeding type and genetic risk of developing coeliac disease on intestinal microbiota of infants: the PROFICEL study. PLOS ONE 7:e30791. doi: 10.1371/journal.pone.0030791

Penders, J., Thijs, C., Vink, C., Stelma, F. F., Snijders, B., Kummeling, I., et al. (2006). Factors influencing the composition of the intestinal microbiota in early infancy. Pediatrics 118, 511-521. doi: 10.1542/peds.2005-2824

Picard, C., Fioramonti, J., Francois, A., Robinson, T., Neant, F., and Matuchansky, C. (2005). Review article: bifidobacteria as probiotic agents physiological effects and clinical benefits. Aliment. Pharmacol. Ther. 22, 495-512. doi: 10.1111/j.1365-2036.2005.02615.x

Putignani, L., Del Chierico, F., Petrucca, A., Vernocchi, P., and Dallapiccola, B. (2014). The human gut microbiota: a dynamic interplay with the host from birth to senescence settled during childhood. Pediatr. Res. 76, 2-10. doi: 10.1038/pr.2014.49

Qin, J., Li, R., Raes, J., Arumugam, M., Burgdorf, K. S., Manichanh, C., et al. (2010). A human gut microbial gene catalogue established by metagenomic sequencing. Nature 464, 59-65. doi: 10.1038/nature08821

Rajilic-Stojanovic, M., Heilig, H. G., Molenaar, D., Kajander, K., Surakka, A., Smidt, H., et al. (2009). Development and application of the human intestinal tract chip, a phylogenetic microarray: analysis of universally conserved phylotypes in the abundant microbiota of young and elderly adults. Environ. Microbiol. 11, 1736-1751. doi: 10.1111/j.1462-2920.2009.01900.x 
Roger, L. C., Costabile, A., Holland, D. T., Hoyles, L., and McCartney, A. L. (2010). Examination of faecal Bifidobacterium populations in breast- and formula-fed infants during the first 18 months of life. Microbiology 156, 3329-3341. doi: 10.1099/mic.0.043224-0

Rondanelli, M., Giacosa, A., Faliva, M. A., Perna, S., Allieri, F., and Castellazzi, A. M. (2015). Review on microbiota and effectiveness of probiotics use in older. World J. Clin. Cases 3, 156-162. doi: 10.12998/wjcc.v3.i2.156

Salazar, N., Lopez, P., Valdes, L., Margolles, A., Suarez, A., Patterson, A. M., et al. (2013). Microbial targets for the development of functional foods accordingly with nutritional and immune parameters altered in the elderly. J. Am. Coll. Nutr. 32, 399-406. doi: 10.1080/07315724.2013.827047

Santacruz, A., Collado, M. C., Garcia-Valdes, L., Segura, M. T., Martin-Lagos, J. A., Anjos, T., et al. (2010). Gut microbiota composition is associated with body weight, weight gain and biochemical parameters in pregnant women. $\mathrm{Br}$. J. Nutr. 104, 83-92. doi: 10.1017/s0007114510000176

Savignac, H. M., Kiely, B., Dinan, T. G., and Cryan, J. F. (2014). Bifidobacteria exert strain-specific effects on stress-related behavior and physiology in BALB/c mice. Neurogastroenterol. Motil. 26, 1615-1627. doi: 10.1111/nmo.12427

Sela, D. A., Chapman, J., Adeuya, A., Kim, J. H., Chen, F., Whiteheadf, T. R., et al. (2008). The genome sequence of Bifidobacterium longum subsp. infantis reveals adaptations for milk utilization within the infant microbiome. Proc. Natl. Acad. Sci. U.S.A. 105, 18964-18969. doi: 10.1073/pnas.0809584105

Sivan, A., Corrales, L., Hubert, N., Williams, J. B., Aquino-Michaels, K., Earley, Z. M., et al. (2015). Commensal Bifidobacterium promotes antitumor immunity and facilitates anti-PD-L1 efficacy. Science 350, 1084-1089. doi: 10.1126/science.aac4255

Stsepetova, J., Sepp, E., Julge, K., Vaughan, E., Mikelsaar, M., and de Vos, W. M. (2007). Molecularly assessed shifts of Bifidobacterium ssp. and less diverse microbial communities are characteristic of 5-year-old allergic children. FEMS Immunol. Med. Microbiol. 51, 260-269. doi: 10.1111/j.1574-695X.2007.00306.x

Taverniti, V., and Guglielmetti, S. (2014). Methodological issues in the study of intestinal microbiota in irritable bowel syndrome. World J. Gastroenterol. 20, 8821-8836. doi: 10.3748/wjg.v20.i27.8821

Tojo, R., Suarez, A., Clemente, M. G., de los Reyes-Gavilan, C. G., Margolles, A., Gueimonde, M., et al. (2014). Intestinal microbiota in health and disease: role of bifidobacteria in gut homeostasis. World J. Gastroenterol. 20, 15163-15176. doi: 10.3748/wjg.v20.i41.15163

Turnbaugh, P. J., Hamady, M., Yatsunenko, T., Cantarel, B. L., Duncan, A., Ley, R. E., et al. (2009). A core gut microbiome in obese and lean twins. Nature 457, 480-484. doi: 10.1038/nature07540

Turroni, F., Peano, C., Pass, D. A., Foroni, E., Severgnini, M., Claesson, M. J., et al. (2012). Diversity of bifidobacteria within the infant gut microbiota. PLoS ONE 7:e36957. doi: 10.1371/journal.pone.0036957

Underwood, M. A., German, J. B., Lebrilla, C. B., and Mills, D. A. (2015). Bifidobacterium longum subspecies infantis: champion colonizer of the infant gut. Pediatr. Res. 77, 229-235. doi: 10.1038/pr.2014.156 van Tongeren, S. P., Slaets, J. P., Harmsen, H. J., and Welling, G. W. (2005). Fecal microbiota composition and frailty. Appl. Environ. Microbiol. 71, 6438-6442. doi: 10.1128/aem.71.10.6438-6442.2005

Voreades, N., Kozil, A., and Weir, T. (2014). Diet and the development of the human intestinal microbiome. Front. Microbiol. 5:494. doi: 10.3389/fmicb.2014.00494

Wang, F., Huang, G., Cai, D., Li, D., Liang, X., Yu, T., et al. (2015). Qualitative and semiquantitative analysis of fecal Bifidobacterium species in centenarians living in Bama, Guangxi, China. Curr. Microbiol. 71, 143-149. doi: 10.1007/s00284015-0804-z

Woodmansey, E. J. (2007). Intestinal bacteria and ageing. J. Appl. Microbiol. 102, 1178-1186. doi: 10.1111/j.1365-2672.2007.03400.x

Woodmansey, E. J., McMurdo, M. E., Macfarlane, G. T., and Macfarlane, S. (2004). Comparison of compositions and metabolic activities of fecal microbiotas in young adults and in antibiotic-treated and non-antibiotictreated elderly subjects. Appl. Environ. Microbiol. 70, 6113-6122. doi: 10.1128/AEM.70.10.6113-6122.2004

Wu, G. D., and Lewis, J. D. (2013). Analysis of the human gut microbiome and association with disease. Clin. Gastroenterol. Hepatol. 11, 774-777. doi: 10.1016/j.cgh.2013.03.038

Wu, X., Ma, C., Han, L., Nawaz, M., Gao, F., Zhang, X., et al. (2010). Molecular characterisation of the faecal microbiota in patients with type II diabetes. Curr. Microbiol. 61, 69-78. doi: 10.1007/s00284-010-9582-9

Xu, M., Wang, B., Fu, Y., Chen, Y., Yang, F., Lu, H., et al. (2012). Changes of fecal Bifidobacterium species in adult patients with hepatitis B virus-induced chronic liver disease. Microb. Ecol. 63, 304-313. doi: 10.1007/s00248-0119925-5

Yatsunenko, T., Rey, F. E., Manary, M. J., Trehan, I., Dominguez-Bello, M. G., Contreras, M., et al. (2012). Human gut microbiome viewed across age and geography. Nature 486, 222-227. doi: 10.1038/nature 11053

Zhao, L., Qiao, X., Zhu, J., Zhang, X., Jiang, J., Hao, Y., et al. (2011). Correlations of fecal bacterial communities with age and living region for the elderly living in Bama, Guangxi, China. J. Microbiol. 49, 186-192. doi: 10.1007/s12275-0110405-x

Conflict of Interest Statement: The authors declare that the research was conducted in the absence of any commercial or financial relationships that could be construed as a potential conflict of interest.

Copyright (C) 2016 Arboleya, Watkins, Stanton and Ross. This is an open-access article distributed under the terms of the Creative Commons Attribution License (CC BY). The use, distribution or reproduction in other forums is permitted, provided the original author(s) or licensor are credited and that the original publication in this journal is cited, in accordance with accepted academic practice. No use, distribution or reproduction is permitted which does not comply with these terms. 